\title{
Short-Term Assessment of Intersphincteric Resection in Low Rectal Cancer
}

\author{
ISMAIEL A. MOURAD, M.D.*; HISHAM A. EL-HOSSIENY, M.D.**; ABD EL-HAMID H. EZZAT, M.D.*; \\ IHAB S. HUSSEIN, M.D.*; MOHAMMAD TAHER FOUAD, M.D.* and RASHA MAHMOUD ALLAM, M.D.*** \\ The Departments of Surgical Oncology*, Radiation Therapy** and Biostatistics \& Cancer Epidemiology***, \\ National Cancer Institute, Cairo University, Egypt
}

\begin{abstract}
Background: Correlation analysis between functional outcomes and different factors (pouch, stoma, ISR type, age and sex) revealed: Pouch formation and type of ISR had significant correlations with some functional aspects.

Aim of the Study: To evaluate the oncologic safety and functional outcomes of Intersphincteric Resection (ISR) as an alternative to Abdominoperineal Resection (APR) in low rectal cancer.

Patients and Methods: Patients presenting to the National Cancer Institute, Cairo University from May 2014 to October 2014; with locally advanced low (3-6m from the anal verge) rectal cancer and ended their long-course neoadjuvant chemoradiotherapy were subjected to ISR if eligible. These patients were assessed and followed for the short-term outcomes of ISR.

Results: Twenty one patients underwent ISR. There was no mortality. Ten patients had postoperative complications.

All cases had free distal margin and one patient had $+\mathrm{ve}$ radial margin. The Improvement of all functional aspects occurred with time. Kirwan's grade of continence by the 15 th month was: I: $5 / 16$ (31.3\%), II: 8 (50\%) and III: 3 (18.8\%). This is very clear comparing it with ${ }^{3}$ month results: II: 3/19 (15.8\%), III: 13 (68.4\%) and IV: 3 (15.8\%).

Conclusion: Intersphincteric resection is an oncologically safe alternative to the standard APR in low rectal cancer, with the added benefit of improving the quality of life by avoiding a permenant stoma, together with acceptable functional outcomes.
\end{abstract}

Key Words: Low rectal cancer - Intersphincteric resectionNeoadjuvantchemoradiotherapy - Coloplasty pouch.

Correspondence to: Dr. Mohammad Taher Fouad, E-Mail: mohammed.taher@nci.cu.edu.eg or : mohamed. taher@57357.org

\section{Introduction}

HISTORICALLY, patients with distal rectal cancers had to undergo APR to achieve adequate oncological clearance. However, an oncologically safe alternatives of APR surgery and accordingly avoiding a permenant stoma is to be considered [1]

Improving survival and quality of life are similarly vital and are the chief goals for the treatment of rectal cancer. Perfect surgery for rectal cancer is not only to achieve adequate distal and circumferential margins, but also to maintain normal sphincter function [1].

Studies recommended that distal intramural spread of rectal cancer seldom extends more than $1 \mathrm{~cm}$ past the distal margin of the tumor. Therefore, a $2 \mathrm{~cm}$ and even a $1 \mathrm{~cm}$ distal margin has increased the rates of sphincter-saving surgeries performed [2]

In addition, it was documented that close circumferential margin $(C R M<=1 \mathrm{~mm})$ is more significant than the distal margin concerning the incidence of recurrence [3]

Intersphincteric resection is a surgical technique where the rectum is resected through the intersphincteric plane. This procedure has abdominal and perineal parts with total mesorectal excision; with total or partial excision of the IAS [4].

The ISR technique is based on the idea that rectal tumors extend into the visceral structures, i.e. proximally the rectum and distally the anal canal; and that there is an embryonic plane of fusion between the visceral structures and the 
surrounding somatic skeletal muscles of the pelvic floor. The aim is to remove the viscus without harming the skeletal muscles [5].

It was found that there is no advantage (in terms of local recurrence, occurrence of distant metastases, and five-year survival) between APR and ISR [6]. Added to this is the advantage of ISR in improving the patients' life quality by avoiding the need for a permenant stoma [2].

\section{Patients and Methods}

This prospective study has been conducted at the National Cancer Institute, Cairo University Egypt.

From the patients with locally advanced low rectal cancer [initial clinical stages II (cT3-4, N0, M0) and III (cT1-4, N+, M0)] who ended their long-course neoadjuvant chemoradiotherapy; and referred to the Outpatient Surgery Clinic within 6 months during the period from May 2014 to October 2014. The patients were assessed and selected according to the following inclusion and exclusion criteria.

\section{Inclusion criteria:}

1- Low rectal cancer: Distal tumor edge within 3$6 \mathrm{~cm}$ from the anal verge.

2- Local spread restricted to rectal wall or Internal Anal Sphincter (IAS) (i.e. T2).

3- Satisfactory preoperative sphincter function and continence.

4- Absence of distant metastasis.

\section{Exclusion criteria:}

1- Tumors with distal edge from the anal verge $<3 \mathrm{~cm}$ and or $>6 \mathrm{~cm}$.

2- T4 lesions (tumors invading the visceral peritoneum or adjacent organs or structures: Including puborectalis).

3- Tumors invading the External Anal Sphincter (EAS) (i.e. T3).

4- Unsatisfactory pre-operative sphincter function and continence.

5- Presence of distant metastasis.

\section{Surgical technique:}

Surgery was done after an interval period of about 6-8 weeks after the end of chemoradiation to gain maximum radiotherapy response. Surgical procedure was performed as described by Schiessel and his colleagues as follows:

1- Abdominal part (patient in the supine position): High ligation of the inferior mesenteric artery with mobilization of the left colon.

- Total Mesorectal Excision (TME), sharp dissection along the embryologic avascular plane between the mesorectal fascia and the fascia of pelvic sidewall; and preserving the hypogastric plexus nerves.

- Dissection down to the levator ani under direct vision.

\section{2- Peranal part (patient in the extended lithotomy} position:

-Wide exposure using lone star retractor.

- Circumferential incision of the mucosa and IAS was started at $2 \mathrm{~cm}$ distal to the distal tumor margin.

- Dissection was continued by mobilizing the rectum proximally through the intersphincteric plane (i.e., between the IAS and the EAS) to meet with the pelvic dissection done through the abdominal part.

Three types of ISR were done:

A- Total: Complete resection of the IAS.

$B$ - Subtotal (modified partial subtype): Where we left a part of the IAS. Incision of the IAS was initiated $2 \mathrm{~cm}$ distal to the lower edge of the tumor below the dentate line on the side of the tumor. On the opposite side of the tumor, the cut line was just above the dentate line to preserve a partial dentate line.

$C$ - Partial: Where we left most of the IAS and almost completely intact dentate line.

- Removal of the rectum en bloc with the IAS per anus and frozen section. All cases had a pathological free distal margin.

\section{3- Reconstruction of the bowel continuity:}

We found that it was more feasible to perform a coloplasty pouch rather than a J-pouch, either because of a bulky mesentry or short bowel length with narrow pelvis and obesity in most patients.

An incision of about $5-10 \mathrm{~cm}$ was made along the taenia away from the stump at least by $5 \mathrm{~cm}$, and then was closed in transverse direction by a onelayer (000) suture.

Thereafter continuity was restored witha coloanal anastomosis. 


\section{4- The creation of a protective ileostomy:}

A temporary (2-3 months) diverting ileostomy was made according to the patient general condition and doubtfulness about the anastomosis.

\section{Follow-up:}

Follow-up was performed every month for the first 6 post-operative months and then every 3 months to the end of the study. The mean followup period was $14.95 \pm 3.11$; range: (3-18 months).

In each visit: The patients underwent digital rectal examination, laboratory assessment. Radiological investigations were done every 3 months (liver ultrasound, chest X-ray) and pelvic MRI was done every 6 months.

Incontinence outcomes were assessed according to the classification of Kirwan and his colleagues. A functional questionnaire was administered to the patients. Patients were asked about:

A- The symptoms of the anterior resection syndrome:

- Stool frequency per day.

- Urgency (inability to defer stool evacuation more than 15 minutes).

- Stool fragmentation (more than 2 evacuations in one hour).

- Dyschezia (stretching to evacuate or taking more than 15 minutes to evacuate).

- Nocturnal defecation.

B- Feces and flatus discrimination.

$C$ - The continence status according to Kirwan's classification:

It has five grades as follows:

Grade I: Perfect continence.

Grade II: Incontinence of flatus.

Grade III: Occasional minor soiling.

Grade IV: Frequent major soiling.

Grade V: Incontinence requiring colostomy.

\section{Statistical analysis:}

Data were analyzed using SPSS win statistical package Version 23. Numerical data were expressed as mean and Standard Deviation (SD) or range. Qualitative data were expressed as frequency and percentage.

Paired comparisons of categorical variables were done by McNemar's test. Paired comparisons of numerical variables were done by paired Student $t$-test as appropriate. Testing for normality was checked by Kolmogorov-Smirnov test.

Comparison between groups to test for group effect with respect to numerical variables was done using Kruskal Wallis test. Comparison between different time periods was tested for time effect with respect to numerical variables using Freidman test that was followed by post hoc pair wise comparison by Wilcoxon matched pairs sign rank test.

Correlation analysis was done using Pearson correlation tests.

$p$-value $\leq 0.05$ was considered significant and every test was 2 tailed.

\section{Results}

\section{Patients and tumor characteristics:}

The study was conducted on 21 patients; 12 females $(57.1 \%)$ and 9 males $(42.9 \%)$. The mean age of the patients was $42.52 \pm 12.15$; range: (2166 years).

The mean of the maximum resting anal pressure before surgery was $197.38 \pm 10.91$; range: (185$220 \mathrm{mmHg}$ ) and that of the maximum squeezing anal pressure was 334.29 \pm 7.3 ; range: (325-350 $\mathrm{mmHg}$ ).

The mean distance of the lower edge of the tumor after chemoradiotherapy was $4.91 \pm 0.72$; range: $(3.5-6 \mathrm{~cm})$. The tumor grades were as follows: GI: 1 (4.8\%), GII: 13 (61.9\%) and GIII: 7 $(33.3 \%)$.

The preoperative tumor stages were as follows: Stage I: 15 (71.4\%) and stage III: 6 (28.6\%).

Detailed preoperative $\mathrm{T} \& \mathrm{~N}$ staging was as follows: T1: 2 (9.5\%) \& T2: 19 (90.5\%). N0: 15 (71.4\%), N1: 5 (23.8\%) and N2: 1(4.8\%).

The technique of ISR:

A- Operative details:

Among the 21 patients: 6/21 (28.6\%) underwent total ISR, 11/21 (52.4\%) underwent subtotal ISR (modified partial type) and 4/21 (19\%) underwent partial ISR.

A covering ileostomy was made in 10/21 $(47.6 \%)$. The mean period of stoma take down was $10.88 \pm 1.36$; range: (9-13 weeks). Coloplasty pouch was constructed in 10/21 (47.6\%). The mean operative time was $226.19 \pm 22.91$; range: (190-260 minutes). The mean of intraoperative blood loss was $300 \pm 52.44$; range: $(200-400 \mathrm{ml})$. There were no intraoperative complications. The mean of the 
hospital stay after surgery was $6.95 \pm 2.29$; range: (4-12 days).

\section{B- Oncological outcomes:}

\section{Surgical margin:}

Negative distal margin was obtained in all patients. The mean of the distal margin was $1.96 \pm$ 0.59 ; range: $(0.3-2.6 \mathrm{~cm})$. Radial margin was positive $(<1 \mathrm{~mm})$ in one patient $(4.8 \%)$. The mean of the radial margin was $1.3 \pm 0.52$; range: $(0.1-2 \mathrm{~cm})$.

Local recurrence, distant metastasis and survival:

Documenting these aspects here are only from the descriptive point of view; as they have no statistical significance because of the short followup period of the study; $14.95 \pm 3.11$ months.

Two patients (9.5\%) developed local recurrence: One had isolated pelvic recurrence on the 13 th month; and the other had (pelvic + nodal) combined with metastasis to the liver and peritoneum on the 16 th month.

One patient died on the ${ }^{6 \text { th }}$ month of dehydration and renal failure. Overall survival during the followup period was $(95.2 \%)$.

\section{C- Functional outcomes:}

Three main items were assessed:

A- Symptoms of anterior resection syndrome:

These include: Urgency, stool fragmentation, stool frequency, dyschezia and nocturnal defecation).

B- Feces and flatus discrimination.

C- Kirwan's grade of continence.

- All these items (A, B \& C) and symptoms have shown improvement with time after surgery (Table $1)$.

Table (1): Descriptive statistics on functional outcome parameters.

\begin{tabular}{|c|c|c|c|c|}
\hline Follow-up data & $\begin{array}{c}\text { 3rd month } \\
\text { FU }(n=19) \\
(100 \%)^{2} \\
\text { cases missing* }\end{array}$ & $\begin{array}{c}\text { 9th month } \\
\text { FU }(\mathrm{n}=19) \\
(100 \%)^{2} \\
\text { cases missing* }\end{array}$ & $\begin{array}{c}15 \text { th month } \\
\mathrm{FU}(\mathrm{n}=16) \\
(100 \%)^{5} \\
\text { cases missing** }\end{array}$ & $\begin{array}{c}p- \\
\text { value } \\
* * *\end{array}$ \\
\hline \multicolumn{5}{|l|}{ Stool frequency: } \\
\hline Mean \pm SD & $8.10 \pm 2.66$ & $6.10 \pm 2.88$ & $5.29 \pm 2.57$ & 0.001 \\
\hline \multicolumn{5}{|c|}{ Stool fragmentation: } \\
\hline Yes n $(\%)$ & $17(89.5)$ & $2(10.5)$ & $1 \quad(6.3)$ & 0.001 \\
\hline No $n(\%)$ & $2(10.5)$ & $17(89.5)$ & $15(93.7)$ & \\
\hline \multicolumn{5}{|l|}{ Urgency: } \\
\hline No $n(\%)$ & $2(10.5)$ & $13(68.4)$ & $11(68.7)$ & 0.001 \\
\hline Yes n $(\%)$ & $17(89.5)$ & $6 \quad(31.6)$ & $5 \quad(31.3)$ & \\
\hline \multicolumn{5}{|l|}{ Dyschezia: } \\
\hline Yes n $(\%)$ & $5 \quad(26.3)$ & $4 \quad(21.1)$ & $0 \quad(0)$ & 0.135 \\
\hline No $n(\%)$ & $14(73.7)$ & $15(78.9)$ & $16(100)$ & \\
\hline \multicolumn{5}{|c|}{ Feces and flatus discrimination: } \\
\hline Yes n $(\%)$ & $0 \quad(0)$ & $6 \quad(31.6)$ & $13(81.3)$ & 0.001 \\
\hline No n $(\%)$ & $19(100)$ & $13(68.4)$ & $3 \quad(18.7)$ & \\
\hline \multicolumn{5}{|c|}{ Nocturnal defecation: } \\
\hline Yes n $(\%)$ & $16(84.2)$ & $9 \quad(47.4)$ & $4 \quad(25)$ & 0.001 \\
\hline No n $(\%)$ & $3 \quad(15.8)$ & $10(52.6)$ & $12(75)$ & \\
\hline \multicolumn{5}{|c|}{ Kirwan's classification: } \\
\hline $1 \mathrm{n}(\%)$ & $0 \quad(0)$ & $2(10.5)$ & $5(31.3)$ & 0.001 \\
\hline $2 \mathrm{n}(\%)$ & $3 \quad(15.8)$ & $9(47.4)$ & $8(50)$ & \\
\hline $3 \mathrm{n}(\%)$ & $13(68.4)$ & $8(42.1)$ & $3(18.7)$ & \\
\hline 4 n $(\%)$ & $3 \quad(15.8)$ & $0(0)$ & $0(0)$ & \\
\hline $5 \mathrm{n}(\%)$ & $0 \quad(0)$ & $0(0)$ & $0(0)$ & \\
\hline
\end{tabular}


- Correlation analysis was performed between each of these items (A, B \& C) on one side and each of; ISR type, covering stoma, Pouch, age and sex; on the other side.

- A significant statistical correlation was found between:

- Urgency and ISR type: (Urgency is less in partial ISR), $r=0.572$.

- Urgency and age:(Urgency is less in old age?), $r=0.670$.

- Nocturnal defecation and pouch: (Nocturnal defecation is less in those have a pouch), $r=$ 0.900 .

- Stool frequency and pouch: (Frequency is less in those have a pouch), $r=0.598$.

- Kirwan's grade of continence and pouch formation (continence is better in those have a pouch), $r=0.539$.

- No significant correlation was found between feces and flatus discrimination with any factor.

We found that continence was better in those underwent subtotal (modified partial) ISR than total and partial ISR ( $p=0.03)$; however; we couldn't elicit any statistically significant correlation. This could be explained by the small number of patients had partial and total 10/21 (47.6\%) compared to those had subtotal ISR 11/21 (52.4\%).

\section{D- Morbidity and mortality:}

There was no operative-related mortality. Ten out of 21 patients $(47.6 \%)$ developed postoperative complications.

Two out of 21 patients $(9.5 \%)$ developed anastomotic leakage presented as pelvic sepsis and collection. They were managed by guided aspiration of the collection and conservative measures (keeping nill by mouth NPO, IV antibiotics and fluids) and they completely resolved within 2 weeks.

Wound infection occurred in 4/21 patients (19\%) and all resolved on repeated cleaning and dressings.

Two out of these patients $(9.5 \%)$ developed intestinal obstruction in the $3 \mathrm{rd}$ and 4 th weeks postoperatively. They were hospitalized and resolved on conservative measures.

Three of 21 patients $(14.3 \%)$ had anastomotic stricture. One patient responded well to repeated manual dilatation and ileostomy take down was delayed till the 13 th week post-operatively. One patient developed dehydration and died in the 6 th postoperative month. The third patient had persistent stenosis despite multiple trials of endoscopic dilatation and has his stoma still in place.

\section{Discussion}

In the current years, APR operation should be considered only in cases where the tumor infiltrates the sphincter complex and in a pre-existing unsatisfactory sphincter function [7].

Two major developments led to dramatic improvements in the oncologic and functional outcomes of ISR: Recognition of the importance of the mesorectum in the spread of rectal cancer and the appreciation of the need to replace the reservoir function of the resected rectum [8].

Regular application of the TME technique consistently resulted in lower rates of local recurrence and with good conservation of post-operative genitourinary function [8].

A diverting stoma aims to protect the primary anastomosis and also to allow three to six months (before take down) for sphincter-strengthening exercises to improve anal function, thus improving anal function after ISR [9].

Neorectal function following ISR may improve with the regular use of a colonic reservoir as $\mathbf{J}$ pouch [10] or coloplasty pouch [11].

\section{Oncological outcomes:}

Bai and his colleagues conducted a study on 85 patients with locally advanced low rectal cancer who received neoadjuvant chemoradiotherapy and then underwent TME with sphincter saving surgery. Negative distal and circumferential resection margins were obtained in all cases. A median followup of 30 months (range, 10-56 months) for 85 patients showed that the three-year overall survival rate was $87 \%$ and local recurrence rate to be $4.7 \%$ (4 of 85). Four patients developed extramural pelvic recurrence.

Distant metastasis occurred in five patients (5.9\%), four with metachronous liver metastasis and one with lung metastasis; and palliative chemotherapy was given [1].

In a study on 30 patients underwent ISR without neoadjuvant therapy done by Tadao and his colleagues, the 5-year overall survival rate was $76.5 \%$. The distal edge of the tumor was $7 \mathrm{~mm}$ (range, 3 to $22 \mathrm{~mm}$ ), and it was negative in all cases. The median circumferential margin of the tumor was $3 \mathrm{~mm}$ (range, 0.5 to $9 \mathrm{~mm}$ ). The circumferential 
resection margin was positive $(<1 \mathrm{~mm})$ in two patients with $\mathrm{T} 3$ tumor.

Local, distant and combined recurrence occurred in four, three, and two patients, respectively. Six patients died of cancer recurrence. For all patients the 5-year disease-free survival rate was $68.4 \%$. The median disease-free interval for six patients with local recurrence was 13 months (range, 8 to 14 months). All of the four isolated local recurrences developed during the first 2 years [12]

In our study, the margin status showed: Negative distal margin was obtained in all patients. The mean of the distal margin was $1.96 \mathrm{~cm}$. Radial margin was positive $(<1 \mathrm{~mm})$ in one patient. The mean of the radial margin was $1.3 \mathrm{~cm}$.

\section{Operative morbidity and mortality:}

The most serious complication of ISR and coloanal anastomosis is anastomotic leakage.

Anastomotic leakage is defined by the presence of a pelvic abscess and is diagnosed by a CT scan or clinical peritonitis [2].

Anastomotic leakage is managed by diverting ileostomy (if not performed in initial operation) or percutaneous drainage.

Intestinal obstruction is defined by a combination of the following findings: Abdominal distention, abdominal pain, vomiting, constipation and the presence of air-fluid levels on a plain abdominal radiograph. Post-operative intestinal obstruction is presented between $0-16 \%$ according to various studies, and most of the patients are managed conservatively [2].

Wound infection is a common minor complication of the ISR surgery. Wound infection is defined by the presence of purulent discharge, erythema, and induration of the wound. Wound infection was reported in up to 9 percent. All of the wound infections were treated by open wound care [2].

We had no intraoperative or post-operative mortality, but there were 10/21 (47.6\%) morbidities. Anastomotic leakage developed in 2/21 (9.5\%) and all resolved conservatively.

\section{Functional outcomes:}

Jia and his colleagues found that, at 12 months after rectal resection, 25/35 patients had good continence (Kirwan Stage I or II), 9 patients had relatively good continence (Kirwan Stage III), and 1 patient had worsened continence (Kirwan Stage IV).
Functional results were similar between patients with a pouch and those without a pouch at different times.

Patients who underwent a modified partial ISR (Kirwan classification; $p=0.004$ to $<0.017$ ) or a partial ISR ( $p=0.008$ to $<0.017)$ had significantly better continence at 12 months than those who underwent total ISR. Patients with a diverting stoma had significantly better continence (Kirwan classification; $p=0.043$ ) than those without a stoma at 12 months of follow-up [9].

Tadao and his colleagues evaluated anal function in patients underwent ISR and correlated them with different factors. They found the following:

The mean Wexner score for all patients was 11.5 (range, 1 to 19 ).

In the patients with partial ISR, the Wexner scores were improved from $13.0 \pm 3.1$ at 3 months to $12.1 \pm 3.0$ at 6 months ( $p=0.04)$. In contrast, in the patients with subtotal or total ISR, no significant differences were found between the Wexner scores at 3 months and 6 months $(13.0 \pm 3.8$ and $11.5 \pm 4.9$, respectively; $p=0.14$ ), but an upward trend was observed in the Wexner scores at 6 months and 12 months ( $11.5 \pm 4.9 \mathrm{vs} 9.1 \pm 5.6$, respectively, $p=0.06)$.

At 3, 6, and 12 months, the Wexner scores were not significantly different between patients who underwent partial and subtotal or total ISR [12].

The results of the univariate analysis revealed that poor anal function, as assessed by the Wexner score, was significantly associated with gender (male; $p=0.047$ ) and the presence of anastomotic stricture $(p=0.018)$ at 12 months. The surgical procedure (partial or subtotal/total ISR), type of reconstruction (straight or colonic J-pouch), and age $(<70$ or $\geq 70)$ were not significantly associated with anal function [12].

In our study, we found that the time rather than any other factor was the most important factor associated with improvement of the parameters of functional outcome: (Anterior resection syndrome, feces and flatus discrimination and Kirwan's grade of continence). There was significant statistical difference in the Kirwan's classification, feces and flatus discrimination as well as symptoms of anterior resection syndrome between $3 \mathrm{rd}$, 9 th and $15^{\text {th }}$ month of follow-up $(p \leq 0.05)$.

Correlation analysis of these parameters was done in relation to: Stoma, pouch, ISR type, age and sex. It revealed that pouch formation had a significant correlation with many aspects of the 
functional outcomes as shown in the section of the results.

\section{Conclusion:}

Intersphincteric Resection (ISR) is an oncologically safe alternative to the standard APR in locally advanced low rectal cancer after receiving neoadjuvant chemoradiotherapy, with the added benefit of improving the quality of life by avoiding a permenant stoma, together with acceptable functional outcomes.

\section{References}

1- BAI X., LI S., YU B., SU H., JIN W., et al.: Sphincterpreserving surgery after preoperative radiochemotherapy for T3 low rectal cancers. Oncology Letters, 3: 1336-40, 2012.

2- CIPE G., MUSLUMANOGLU M., YARDIMCI E., MEMMI N. and AYSAN E.: Intersphincteric resection and coloanal anastomosis in treatment of distal rectal cancer. International Journal of Surgical Oncology, 2012.

3- WIBE A., RENDEDAL P.R., SVENSSON E., NORSTEIN J., EIDE T.J., et al.: Prognostic significance of the circumferential resection margin following total mesorectal excision for rectal cancer. The British Journal of Surgery, 89: 327-34, 2002

4- SCHIESSEL R., NOVI G., HOLZER B., ROZEN H., RENNER K., et al.: Technique and long-term results of intersphincteric resection for low rectal cancer. Diseases of the Colon and Rectum, 48: 1858-65, 2005.

5- SCHIESSEL R. and METZGER P.: Intersphincteric resection for low rectal tumors, 1 st ed. In 'The laparoscoic technique of intersphincteric rectum resection', Metzger P. Springer Wien, New York, pp. 85-97, 2012.

6- BRAUN J.,TREUTNER K.H., WINKELTAU G., HEIDENREICH U., LERCH M.M., et al.: Results of intersphincteric resection of the rectum with direct coloanal anastomosis for rectal carcinoma. The American Journal of Surgery, 163: 407-12, 1992.

7- SCHLAG P.M.: Surgical Sphincter Preservation in Rectal Cancer. The Oncologist, 1: 288-92, 1996.

8- KEIGHLEY M., WILLIAMS N., CHURCH J., PAHLMAN L., SCOTT N., et al.: Surgery of the anus, rectum $\&$ colon, $3 \mathrm{rd}$ ed. In 'Management of carcinoma of the rectum', Keighley M, and Williams N. Elsevier Ltd, Hungary, pp. 1115-262, 2008.

9- JIA G.H.,GUANG H.W., ZHI G.G., ZHENG Y. and ZHEN J.W.: Intersphincteric resection with direct coloanal anastomosis for ultralow rectal cancer: The experience of People's Republic of China. Diseases of the Colon and Rectum., 52: 950-7, 2009.

10- BRETAGNOL F., RULLIER E., LAURENT C., ZERBIB F., GONTIER R., et al.: Comparison of functional results and quality of life between intersphincteric resection and conventional coloanal anastomosis for low rectal cancer. Diseases of the Colon and Rectum., 47: 832-8, 2004.

11- PIMENTEL J.M., DUARTE A., GREGÓRIOC, SOUTO P. and PATRÍCIOJ: Transverse coloplasty pouch and colonic J-pouch for rectal cancer-A comparative study. Colorectal Disease, 5: 465-70, 2003.

12- TAKEMOTO M., SUGIURA F., TOKORO T., OKUNO K., UEDA K., et al.: Analysis of the clinical factors associated with anal function after intersphincteric resection for very low rectal cancer. World Journal of Surgical Oncology, 11: 24, 2013.

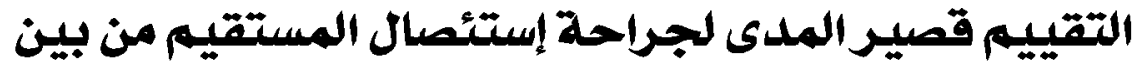

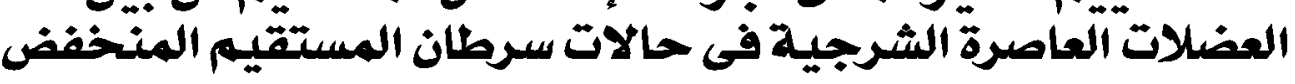

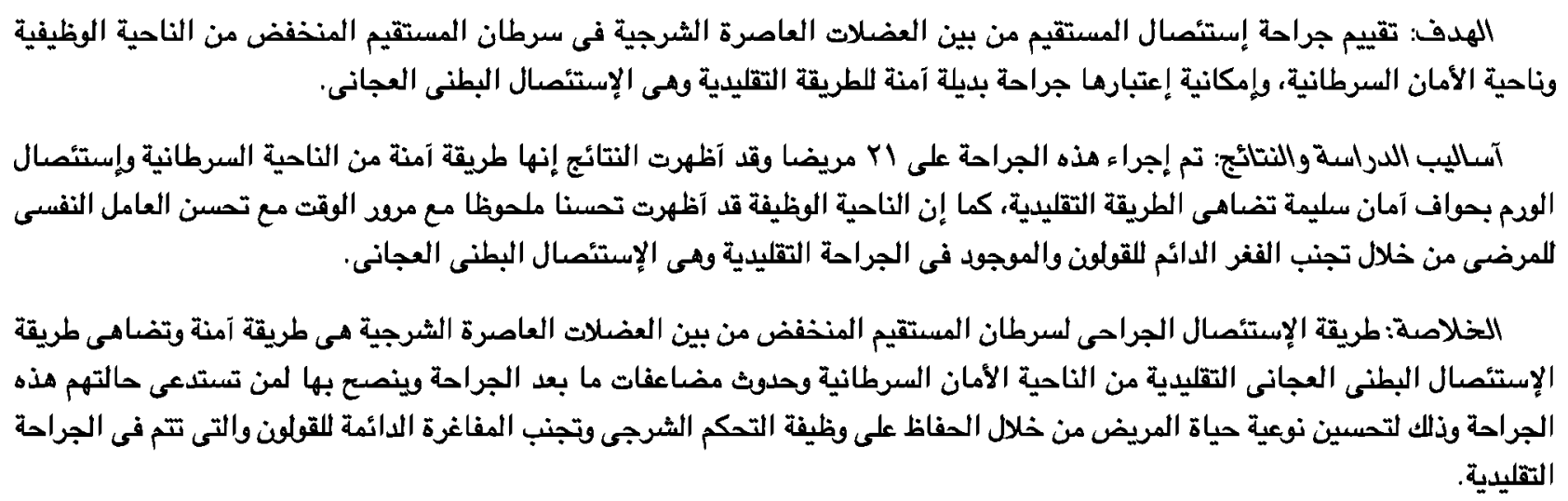

